\title{
Brand Communication during an Unprecedented Time
}

\author{
Muskan Varma
}

\begin{abstract}
All of us are stuck in dilemmas due to this unprecedented period. With people even brands are grappling to secure their routine, employees, customers and profits. Hence, the objective of the study is to focus on how brands need to communicate during pandemics. Both internally (employees/managers /BOD/etc) and externally (customers/ suppliers/ public group/etc). The methodology used is survey, which was target to Indian consumers only. Backed up with secondary data.
\end{abstract}

The results show that:

Brands should advertise normally during the pandemic.

$>$ Consumers are more favorable towards products/brands with digital advertisements that are adjacent to COVID content

Consumers want to hear from brands that offer essential products (healthcare, groceries, household goods, etc)

Consumers prefer to hear from Employees that are on the front line (doctors/nurses/police)

$>$ The most preferred channel for consumers is social media advertisements and TV advertisements.

To conclude brands, need to spread positivity, engage and educate the audience with digital touchpoints and communicate empathetically. 


\section{Table of Contents}

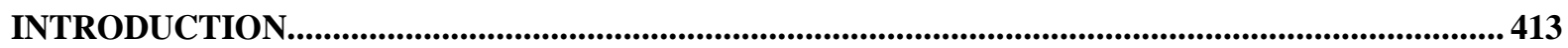

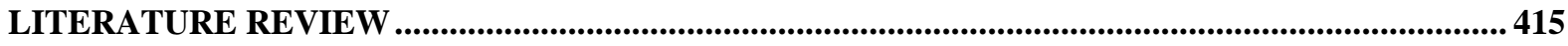

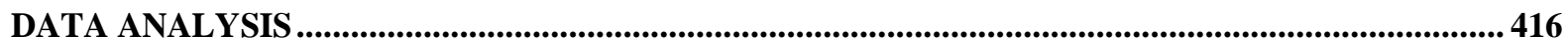



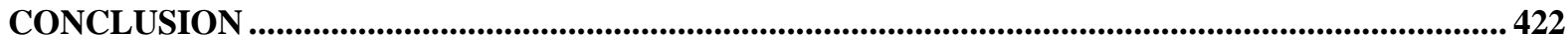




\section{INTRODUCTION}

In recent history, COVID-19 has created an unprecedented time for the entire world. Where it has changed the day to day routine of how the world normally works. In response to combat COVID-19 worldwide economy is closing down (salary deduction, budget freezes for companies or layoffs) and throwing businesses into an encounter with uncertainties, which only increases the importance of communication.

Businesses are grappling to secure the wellbeing of their employees, their own organization's viability for the upcoming destiny and dealing with competency of the work from home system. Survival mode is on for everyone, which puts companies into dilemma if they should continue brand communication or stop all of it. Nonetheless, it is important for brands to pay attention on truth and proactive based communication with all internal and external stakeholders.

Worldwide, we view many leaders communicating proactivity about this pandemic. For example, Head of state in Singapore ${ }^{1}$ are putting an end to citizens fears and unease of COVID-19. Lee Hsien Loong, the PM of Singapore is continuously addressing the citizens through traditional and social media to give light on the situation, deal with their concerns and how to tackle this situation. Therefore, its crucial to find an optimal equilibrium between unrequired information (which may cause hysteria) and clarity in communication.

At least in the short run, there is no doubt that time will be difficult ahead for few brands and the advertising industry ${ }^{2}$. According to a study ${ }^{3}$ from market research firm called Perksy/Berlin Cameron, $43 \%$ of millennials think that brands play a crucial role during this pandemic. However, many companies are postponing their campaigns, almost $50 \%$ of millennials think that they should resume their efforts during this time.

Due to stoppage of work and quarantine the situation for marketers is altering. Promotional, advertising, media and marketing spends, pushing brands and businesses to reconsider and re-evaluate their perception on the current and future marketing and advertising campaigns in order to keep a constant flow of income. For instance, it is challenging to connect with the audience digitally. However, it is necessary for brands to communicate efficiently regardless of their experiences. For this to occur, brands need to learn and adapt continuously this new business climate as it would go a long way ahead for all of

${ }^{1}$ Dash, U. (2020). COVID-19: Why brand communication is the need of the hour. $r$

${ }^{2}$ Mandese, J. (2020). Ad Market Holds Steady In February, The Last 'Normal' Month For A While. g

${ }^{3}$ Faw, L. (2020). Many Millennials Believe Brands Should Step Up Communication During Pandemic. us- how brands and businesses need to alter marketing budgets and plans, alter the way they talk to customers on online platforms, prioritize, transform, seek the correct tone and find effective and new methods to communicate with their clients and employees. In order, for businesses to avoid myopia brands need to redefine he way they interact with their customers. This will cause a raise in the competition and demand for aggressive and creative marketing practices.

As brands are figuring out how to advertise services and product during this crisis, government agencies are monitoring closely to terminate COVID-19 scams, if businesses are deceiving or conducting any potential unfair business practices as citizens are vulnerable. In India, strict actions are taken against individual who spread rumors and create panic. Punishments include imprisonment/fine ${ }^{4}$. During this phase of "infodemic", which $\mathrm{WHO}^{5}$ explains as information overabundance, where some are accurate and some aren't, which makes it hard for individuals to trust sources and find reliable guidance. This is one of the challenges startup or global brands are facing during this pandemic. There are many more such as:

- Rivalry. In other terms other companies/organization competing for the same money as yours. Even though, you have discovered or constructed something no one else has, still there are other companies competing for the money and attention from your target market.

- Restricted Marketing Budget. Usually, startups work on a tight budget and even if startups have huge funding, investors to give an account to. The concern lies in a perceived disadvantage about viable marketing strategy. Yes, marketing requires money but there is no other way to overcome that.

- Concentration. The challenge does not end when the top marketing strategy is made. If the team is inattentive to their obligation, opportunities can be lost and even the best marketing strategy might fail.

- Bombardment of marketing alternatives. Increase in popularity of social media and digital journalism caused an increase to inundation of digital marketing.

Hence, to overcome such challenges it is vital to communicate properly. Even if it talking to your general public, customer and workforce there has a to be momentum of two-way communication for constant information flow that aids to reduce mistakes and raising profits.

External communication (EC) strategies and internal communication (IC) strategies differ as the message for each are not the same. Utilizing different channels to different audiences by using different messages will aid the company to distinguish between their aims and focus. Both

\footnotetext{
${ }^{4}$ Khushbu,J.(2020) Disinformation in times of a pandemic, and the laws around it.

${ }^{5}$ Advice for public. (2020).
} 
internal and external communication approaches are required, working to accelerate organizations message to all its target market.

\section{Meaning}

Internal- it's all regarding employees of the company. The way information passes on within the organization varies, for example, informal, formal (to relay key information), free flow, etc

External ${ }^{6}$ - Its regarding how well the brand can grab the attention of the public. As values are needed to deliver to the customers and connect with public at large. The approach is mainly formal as messages are relayed from top leader through pre-defined channels and later with the official documentation, for example, television, social media, annual reports, customer feedback, etc.

\section{$>$ Motive}

Internal communication strategy promotes and sets out numerous objectives, creates plans to reach these goals either by training or motivating so employees are productive and do their best.

External communication strategy motive is to provide the company's marketing mix with the public. It concentrates on product offering, broadcasting of the brand, development and personality to customers and potential customers.

\section{$>$ Audience}

Internal- mainly inside the organization. The goal is to transmit important information between various departments through effective internal communication ${ }^{7}$ and to make sure that employees are working with the same level of understanding and knowledge.

External- focusing to construct brand awareness for worldwide public. It doesn't just stop at customers, as everyone is important to communicate with in order to have a successful business and create an impact on them.

\section{$>$ Frequency}

Internal- crucial to have continuous flow of updates and information. Its usual in companies to have internal communication mistake ${ }^{8}$ to give news in a sporadic fashion, this leaves the employees in short term information blackout.

External- It is less frequent as there is a risk of overload of information if brands try too hard.

Hence, it is crucial to have a balance of the two. Sending messages too infrequently or too often ends up you

${ }^{6}$ Sinclair, S. (2020). This is why internal and external communication should join forces.

7 Terry, M. (2020). Eight Tips for Effective Internal Communication. $\mathrm{n}$

${ }^{8}$ Terry, M. (2020). 5 Internal Communication Mistakes and How to Avoid Them. are losing them. There are several reasons why external and internal communication needs to go hand in hand, such as:

\section{- Strategic alignment ${ }^{9}$}

If the teams from internal and external communication departments aren't working together then it's not possible to gain a better strategic alignment with different stakeholders. A report ${ }^{10}$ showed that just 14 percent of the organization employees understood the company's direction and strategy. If internal communication performs a decent job by apprising the external communication division on what they are currently working on, there are higher chances of achieving the goals and comprehending the general business strategy.

\section{- Developing more captivated content}

As the workforce eagerly want to know about their good results and achievements. However, a lot of insights can be gained from organization's customers through external communication. Together both the departments can give content that workforce are often trying to engage. Nowadays, it common for external and internal forces to join and establi8sh a more engaging, useable and sharable content. For large companies, if there aren't right internal communication tools it is very hard to achieve such high goals. As all employees need to be tied down to one single communication platform so that the right employee receives the correct message.

\section{- Merge external and internal messaging}

It is pretty common to see external and internal messages to not be completely aligned. Instance, if the organization give contrasting information to investors and employees, then the company will have to deal with many demotivated and disconsolate stakeholders, which may head to bigger problems. Hence, alignment ${ }^{11}$ of the organization is very important for both the sides.

\section{- Developing a sense of unity}

In order to have optimistic employees one of the best ways is to develop unity within the workforce.

\section{- Comprehending audiences}

In order for businesses to gain a unified and wellplaced communication strategy, they need to look at both external and internal audiences. For instance, if businesses are creating their brand message, it is important to develop and take point from both external and internal stakeholders as this approach aids to develop a message that will attract and motivate the employees. People say it's important to treat your employees right just like you would treat your customers. However, not many companies abide by this. If

\footnotetext{
${ }^{9}$ Internal Communications: How to Align Employees with Your Strategic Goals?. (2020).

${ }^{10}$ Witt, D. (2020). Only $14 \%$ of employees understand their company's strategy and direction.

118 Reasons Why Internal Communication Is the Key to Organizational Alignment. (2020). s
} 
they adopted this ideology, they would have been a step closer to success. Paul Barton ${ }^{12}$ says employees can comprehend the audience well and gain better/equal treatment compared to their customers if both internal and external communications work together.

\section{- Aiding workforce to be brand representatives ${ }^{13}$}

Brand representatives are of extreme value, they aid companies to allure talented employees, create brand awareness and boost up sales. Radhika Subramanian said in one of her $\mathrm{CMO}^{14}$ articles that many a times internal stories hold a possibility of sharing externally. Internal communication finds a path to the outside world easily! By using various social media platforms. However, if these are hard to conduct or very complicated, employees will not take actions to be brand representatives.

\section{- Developing trust within customers and employees.}

Across the world developing trust among employees is a key goal. If messages aren't unified between external stakeholders like customers and employees, then it is inevitable for organization to develop distrust. Even now very few employees trust their collogues, this is due to the lack of amalgamate of internal and external communication. Both departments should make sure that the messages which are delivered to the audiences are not contradictory.

\section{- Comprehend and agree on one task}

EC needs to make sure that their efforts, for example a campaign should be known by the IC department. Moreover, IC has a responsibility of communicating to employees about their efforts. This aids all stakeholders to comprehend and agree on the same task/activity, which puts them one step closer to the goal. Hence, all communication flat forms should be integrated in order to extract information quickly and then shared.

\section{- Being plugged into the latest trends of the industry}

Both department's job is to communicate the trends of the industry and market effectively. However, for this to work both departments need to be alignment about providing the exact information to internal and external stakeholders. Employees are supposed to know everything that has to be communicated to the customers now or in the future. However, there should not be information overflow. As not all employees have to everything as this will affect negatively on employee engagement due to overflow of irrelevant information. Due to this reason, IC department needs to execute an IC technology that allows managers and employees to develop customized news based on their priorities and interests.

13 Employee Advocacy | Reach and engage your entire workforce | Smarp. (2020).

\section{- Internally aligning the brand reputation}

Traditionally, businesses main focus is EC, forgetting just how important their internal audiences are. It is crucial that no gaps exist between customer service, advertising attempt, customer service and the product. If there is a gap the best way to close would be to align the brand image completely form inside the organization first. Indicating that not only employees need to comprehend the brand goal but also their part in keeping it that way, with necessary tools and knowledge to deliver what has been expected from them.

Hence, to achieve this it is crucial for both IC and EC to work together as a team.

The entire world is stuck in the same boat. Pondering and navigating through the unexplored water route. Where nobody has a book of answers. Stuck in dilemmas! One of them being communicating effectively. Hence this paper focuses on how brands need to communicate during pandemics. Both internally and externally and strategies for the same. This will aid business to be in a better position when everything returns to "normal".

\section{LITERATURE REVIEW}

\section{$>$ Literature Review (2-4) \\ - Literature review 15}

Communication in the media with respect to a probable avian flu pandemic can provide precise and viable advice to the general society OR misguide and add to unnecessary open panic and ensuing unfortunate reactions. Governments have the opportunity to create communication systems and explicit messages that can viably pass on important data at various phases of the foreseen pandemic. Effective social advertising joins the ideas of developmental research, crowd division, and consumer focus. Based on the discoveries from prior research on public mindfulness and comprehension of bird influenza, the partners of the task created proof based promoting messages for two essential time-points in pandemic preparation and tried in a sequence of focus groups; altered them dependent on the findings; and re-tried the last campaign. These discoveries give significant suggestions for the advancement of future social promoting campaigns in case of pandemics or other general wellbeing emergencies.

\section{- Literature review 16}

A number of marketing departments will consider new creative marketing strategies that will portray their businesses during this new ordinary. Most of the industries

15

]https://ro.uow.edu.au/cgi/viewcontent.cgi?article=4439\&c ontext=hbspapers

16

https://www.hklaw.com/en/insights/publications/2020/04/th e-impact-of-covid19-on-your-advertising-and-marketingcampaig 
will be financially affected which will lead companies to manage market adjustment, given that customers and the new ordinary will see an expanded rivalry amongst businesses. This will demand sustainability from businesses, analyzing changes, threats and problems by strategic arrangement in a vulnerable range; evaluating organization reputation complications; recognizing potential products, services that will fulfil customers' wants while focusing on inventive and key marketing strategies and targeted advertising; and making effective use of social media.

These are made even more significant due to COVID19 , marketing spending is relied upon to diminish for some in 2020 as stores close and income diminishes. For instance, one online rental home booking organization reported that it will suspend all promoting exercises in 2020 so as to spare a huge amount of money. Different organizations have pulled together their spends to reason driven showcasing, strategic advertising and cause-related promoting to satisfy customers' expanded media utilization while working from home. For instance, 45 percent of worldwide customers are giving more opportunity to social media, online streaming has expanded by 26 percent, webbased gaming traffic has expanded exponentially on one media transmission organization's servers, and the quantity of buyers utilizing on the web food conveyance and basic merchandise conveyance has risen significantly.

The result being, a number of companies might be looking to customize their advertising practices in order to increase their online transactions, traffic and time with customers.

\section{- Literature review 17}

Epidemic influenza: A worldwide difficulty for social media marketing

Recent years have seen expanded consideration and concern with respect to the potential for the pandemic, following huge scope flare-ups of pig influenza and bird influenza. Governments and wellbeing organizations have the opportunity to create social advertising procedures and explicit messages that can possibly limit fear, refute or inoculate against the incorrect information the society might face, and upgrade the probability of individuals taking the suggestion medicinal and preventative measures, which are vital. This research paper outlines how to handle the pandemic by promoting socially. The pandemic potential portrays an important test for social advertisers (alongside, wellbeing administrations, governments, and organizations). The various factors about the pandemic flu potential makes it very unique for most of the issues, to where social advertising is applied. The fundamental standards of social marketing are similarly appropriate to a

\footnotetext{
${ }^{17}$ Jones, S., \& Iverson, D. (2012). Pandemic influenza: A global challenge for social marketing marketing. Health, 04(10), 955-962. doi:
}

worldwide pandemic. These times should be used by marketers to build up the aptitudes and assets to label future infectious illness episodes. This research paper puts in the ideas of social advertising, an exceptional medical problem which can possibly get one of the biggest worldwide public health crises ever, yet which can be handled with successful worldwide social marketing.

\section{DATA ANALYSIS}

Due to COVID-19 brands are either pausing or pulling their spending on advertisements. This is causing a lot of stress on businesses. However, looking at the data provided below, shows that consumers do not want businesses to completely stop advertising.

Survey taken in may showed that nearly 4.4 out of 10 Indian respondents ages $13-35$ agreed and about $20.3 \%$ were neutral, contrast to $15.9 \%$ who disagreed. 


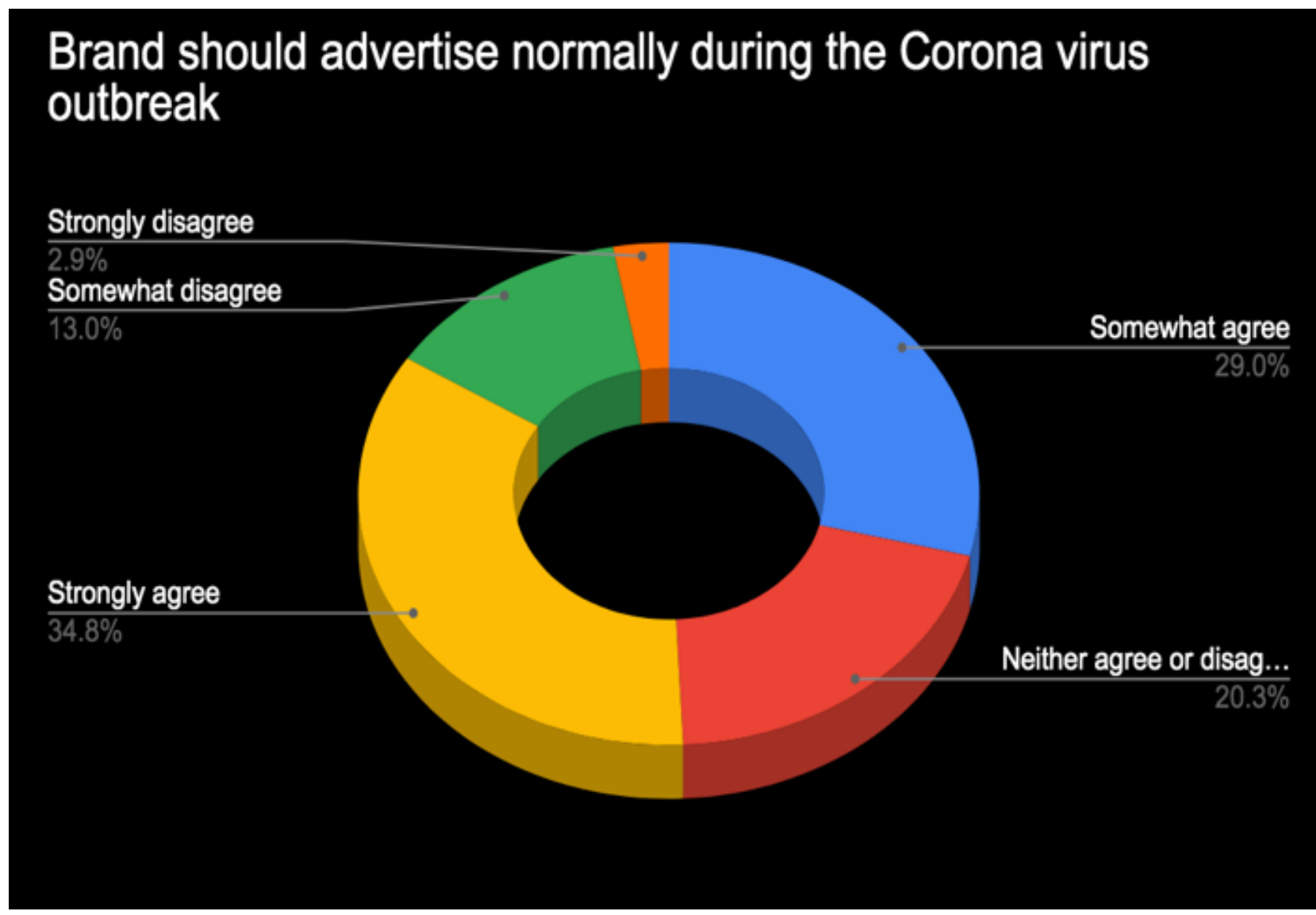

Fig 1

A survey conducted by $\operatorname{Kantar}^{18}$ in March 2020 showed that very few consumers about $8 \%$ in thirty countries think that brands should prioritize terminating advertisements. Whereas, $77 \%$ expected brands to talk about how helpful the brand is during this new routine in life and about $75 \%$ respondents wanted to know about the brands efforts to overcome this situation. Suggesting brands need to reevaluate their plans, as brands are abandoning advertising which most of the consumers do not want. However, pre-planned campaigns which were not related to the pandemic are not suitable for consumers, as they clamor for information of brands actions responding to the pandemic.

Guidance has been provided by GlobalWebIndex on what these actions should be taken. As in the USA about $59 \%$ agreed that they should aid in the production of essentials and suspend their factory production. $80 \%$ respondents agreed that flexible payments should be provided by brands, $70 \%$ of internet users think brands should provide free services and $60 \%$ want non- essentials stores to be closed.
Furthermore, Ace Metric an advertising analytics organization published a paper in mid-March showcasing that about $86 \%$ respondents from USA are open to advertisements mentioning COVID-19. About 42\% responded that any mention of the pandemic would be OK, this is on almost at par with who depending on brand or the message (44\%). Many brands' advertisement may continue during this time and may feel threaten of advertisements which are related to COVID-19 content. As $30.40 \%$ shows that their views on brands would be unchanged if the advertisements were adjacent to COVID-19 content vs $50.7 \%$ would have more favorable opinion.

18 Mohanty, S. (2020). Brands in a pandemic world: insights from Kantar's COVID-19 Barometer | WARC. 


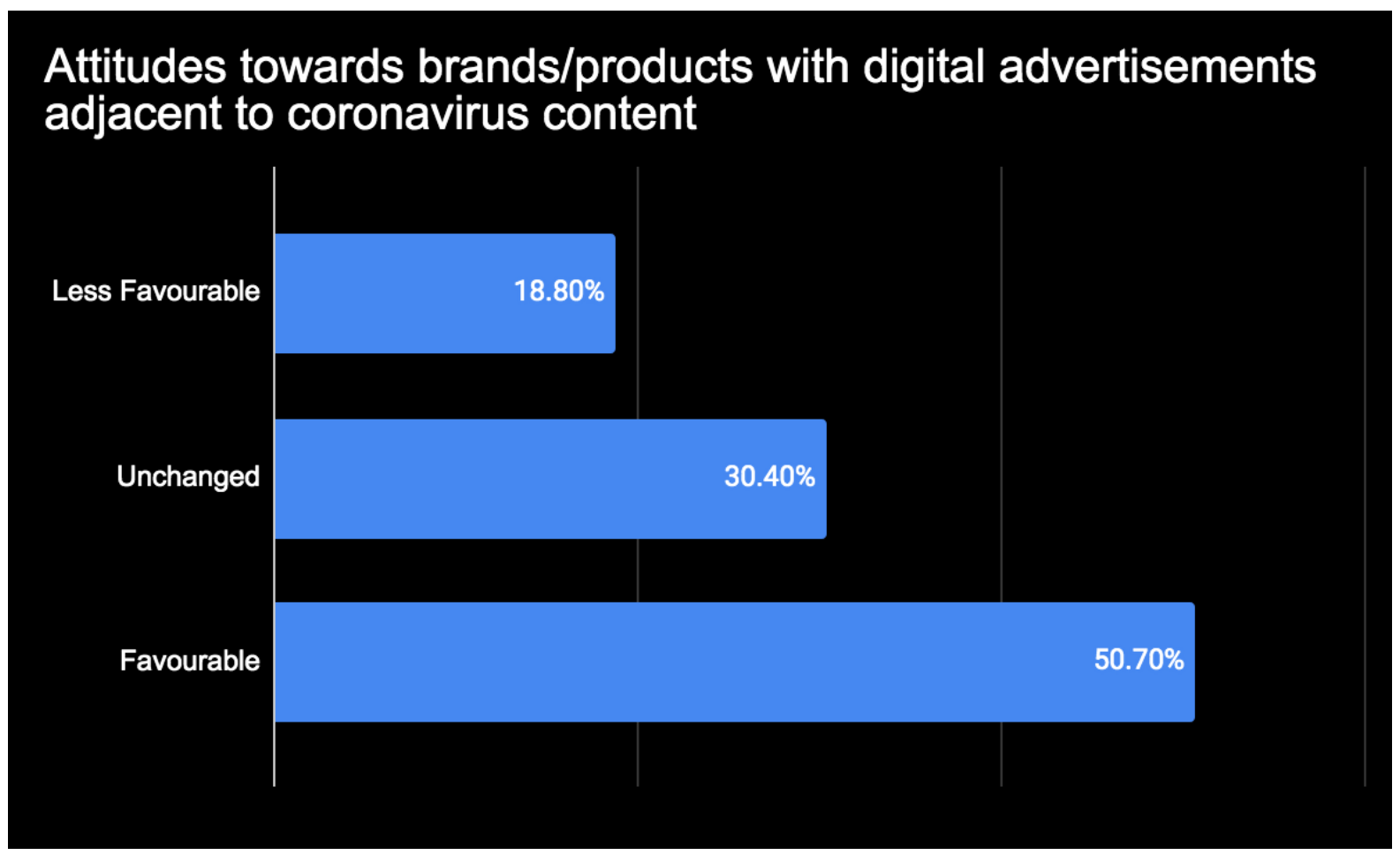

Fig 2

However, when asked to the USA internet users (survey conducted by Integral Ad Science ${ }^{19}$, it showed that $78 \%$ of the responded would have unchanged attitudes towards brands/ products who covered coronavirus content, whereas, only $16 \%$ would be less favorable. This might be due to the cultural difference that exits between Indians and other cultures.

Regardless of buyers' transparency, advertisers need to work cautiously. Likewise, with other social or strategic publicizing strategies, organizations can in any case get COVID-19 messages incorrect to their audience. Brands apparent as exploiting the situation or not paying attention to this serious situation might get confronted with a kickback. In the study done by Kantar, $75 \%$ respondents don't want brands to utilize this circumstance by deriving benefit from it. Additionally, advertisers should eschew using a humor tone.
According to consumers, they wanted to hear more from brands which provided essential goods, such as: grocery stores (59.4\%), household goods (55.1\%), healthcare/pharmaceutical $(63.8 \%)$ food and drink $(39.1 \%)$. Additionally, brands that provided financial services (40.6\%, due to salary cuts and job lost) and charities ( $42 \%$, to aid daily migrant workers or others who have immensely been impacted due to COVID-19) were crucial for consumers as they wanted to hear more from them during this pandemic. On the other side, less from brands that aren't that applicable to the current crisis such as: fashion \& beauty (56.5\%), gym \& fitness (56.5\%) and automotive $(53.6 \%)$.

\footnotetext{
19 Marlow, T. (2020). Consumers on Coronavirus: Ad
} Adjacency Considerations - IAS Insider. 


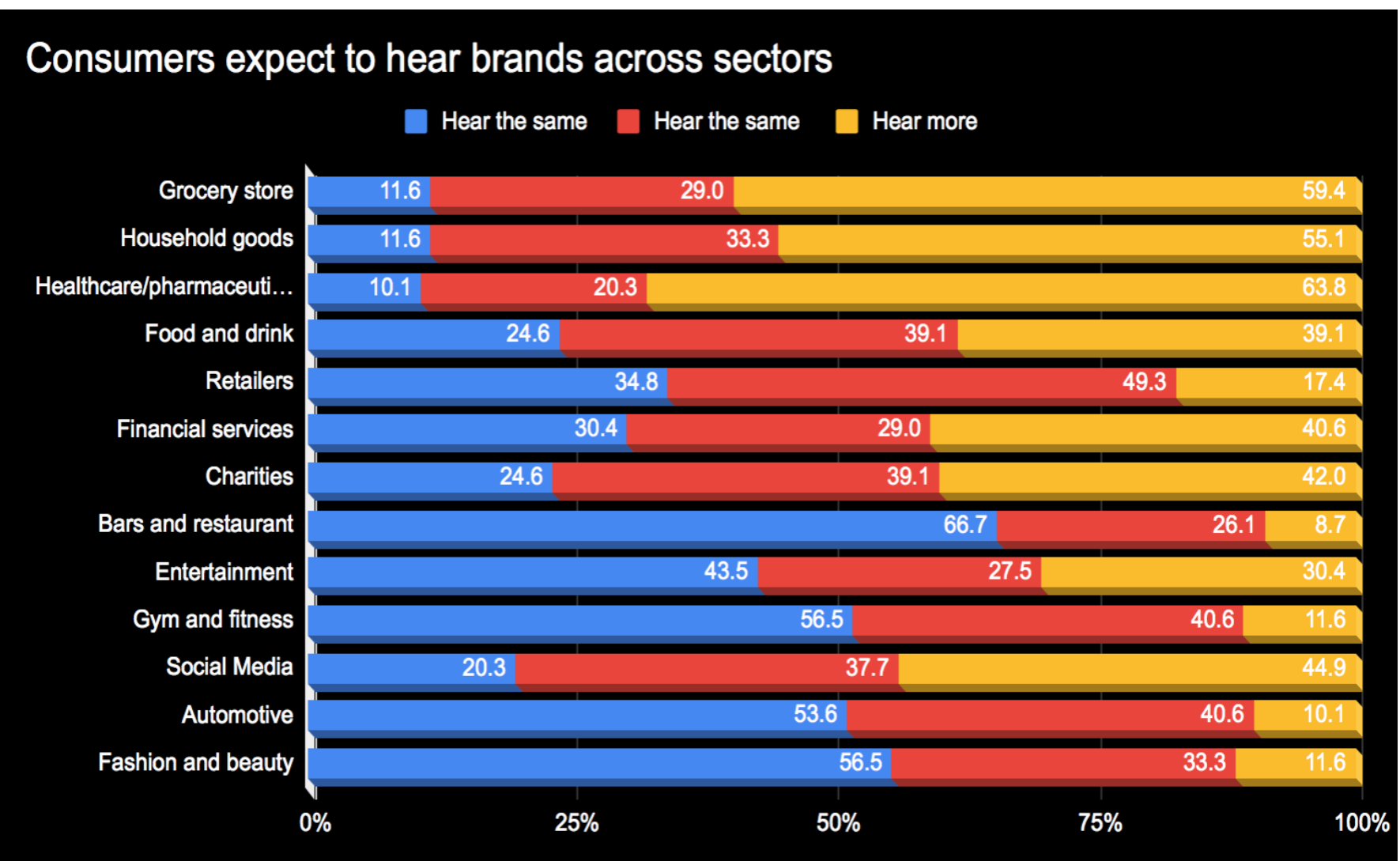

Fig 3

\section{Legitimacy has always been prime}

There is nothing new about consumers hesitation about a brand and their authenticity. As many people are quarantined at home, consumers want to seek content from employees $(47.8 \%)$ and their day to day experience conducting their plans to deal with the virus. Even though we are currently going through an unprecedented time, few rules from before are still applicable. People want to hear from experts $(23.2 \%)$ in order to increase its validity. On the contrary, consumers want to hear less from $\mathrm{CEO} /$ founders (11.6) and celebrity and influencers (17.4\%)

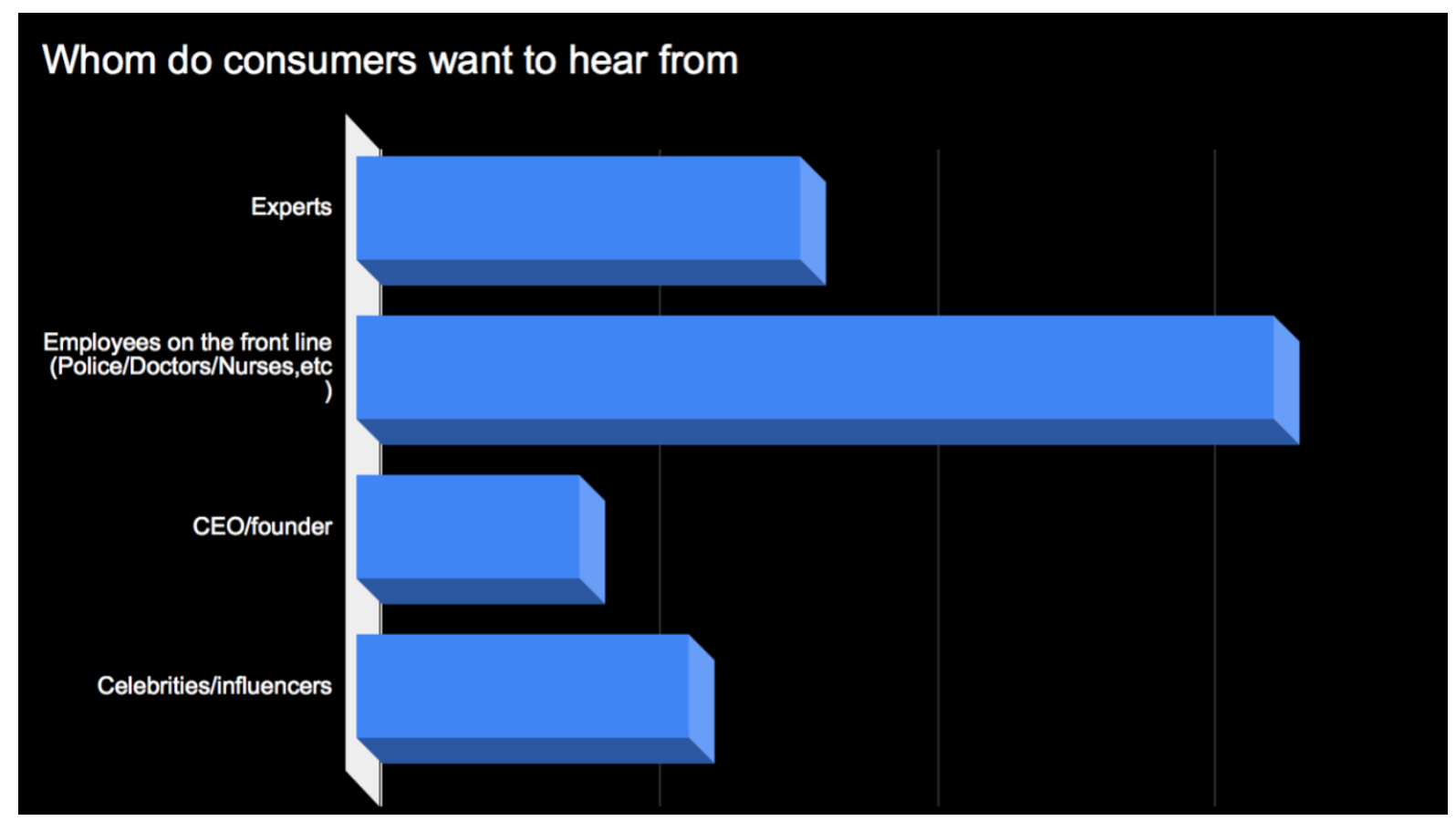

Fig 4 
India had the biggest lockdown in the entire world. Having millions of people stuck at home, trying to pass through this troublesome period, increasing the screen time for TVs than ever before. Hence, providing brands with opportunities to reach large audiences by booking slots in the daytime which are cheaper as now almost everyone's home. In India about 75.6\% respondents proffered channel for advertising was television, alongside social media advertisements (75.4\%) and online advertisements $(47.8 \%)$.

\section{What are the preferred channels}

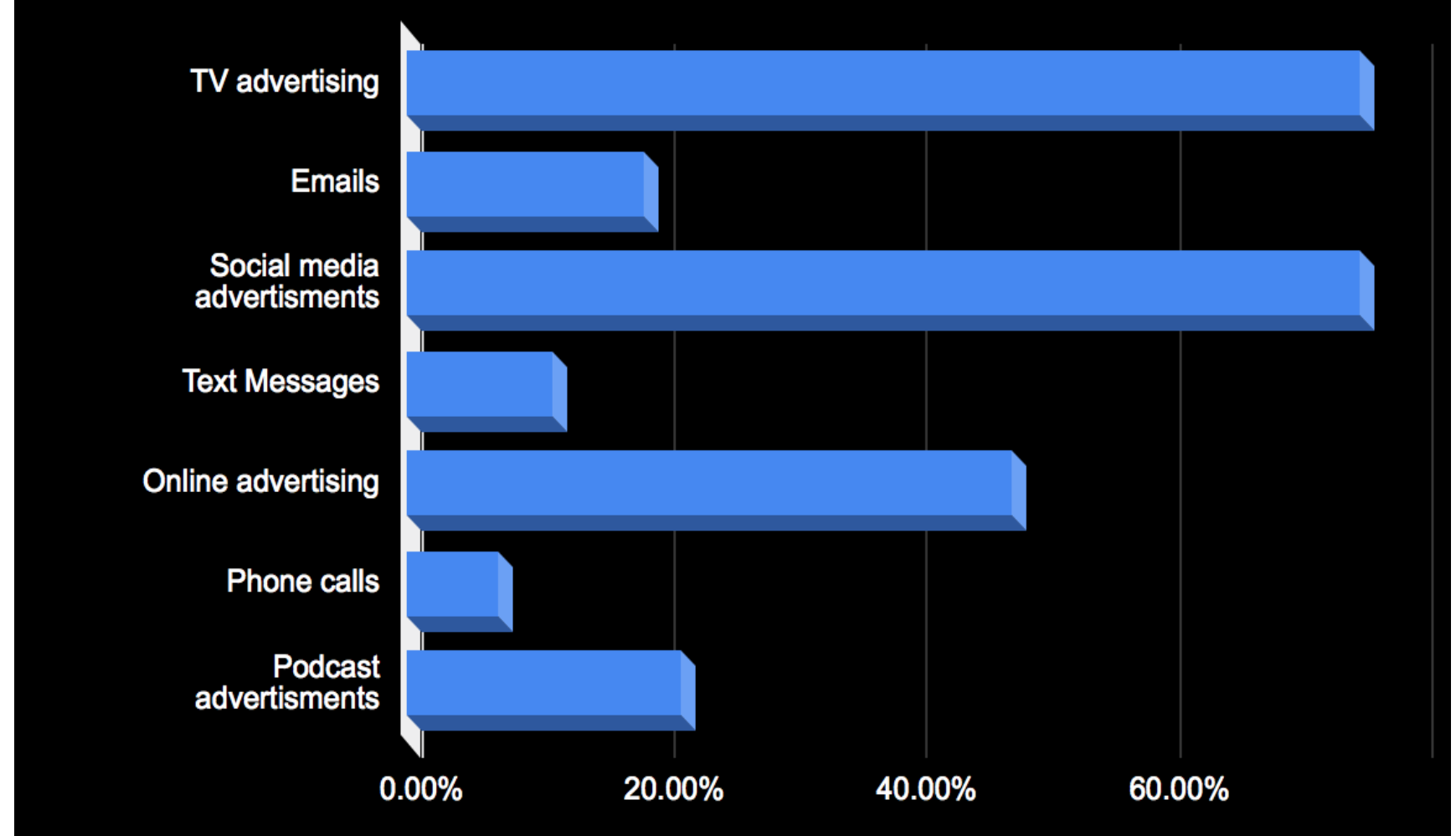

Fig 5

\section{FINDINGS}

Tips for brand communication for external stakeholders

\section{Spread positivity ${ }^{20}$}

Being optimistic is a very good characteristic and spreading that to the external stakeholders during this crisis of negativity will help the brand to stand out. This can be done by giving positive information or spinning the information by extracting just the good part. Make sure that the brand has a balance of positivity and honesty. Here are few of the techniques and examples that will aid brands to increase their own sales and engagement:

\footnotetext{
${ }^{20}$ Dan.(2020).COVID19 | Positive brand communication techniques.
} 




Fig 6 
Engage and educate the audience with digital touchpoints ${ }^{21}$

Company's goal should be to retain trust, this will happen by educating them by developing awareness about precautionary measures for covid-19. Grab the attention of the consumers with not only bold headlines but also eyecatching visuals for the company's target audience. Companies need to engage the public as everyone is trying to grab their attention, but your company needs to stand out from the others.

\section{Empathetically communicate}

The uncertainty of the situation makes the public more vulnerable and frightened. Therefore, kind messages and gestures from brands will be much appreciated. This build up goodwill and trust and shows the public that your brand is really concerned about their stakeholders. Any action a brand takes can be pernicious or magnificent. c

\section{CONCLUSION}

As advertisers get enveloped with what the specialists, believe, as opposed to the public's thought process, doing and feeling. In this paper there are many perceptions about how businesses and brands should react, why and what they should say during this pandemic. Last few months have been very turbulent for all of us. Keeping in mind that it's not that difficult to voice out our perceptions, we also need to tune in to what others have to say. Even though, the sample size for the survey was small and not representative. It helps us getting an in-depth knowledge which have been picked with this sample size. Brands need to get over this fear or dread to prevent them from communicating with their audience. Numerous marketeers believe that brands have come out portraying this period of emergency as a 'tightrope'. The brand that makes the most use of this opportunity by connecting with the consumers rather than seeing this situation as disingenuous will climb the ladder to bigger and better chances of success.

\footnotetext{
21 Jain, K. (2020). Effectively managing brand communication amidst COVID-19 pandemic - ET BrandEquity. Retrieved
} 